\title{
A SYSTEMATIC PROCEDURE TO STUDY HOT PRESSING AND SPARK PLASMA SINTERING KINETICS
}

\author{
İsmail Özgür ÖZER ${ }^{1, *}$, Çetin Meriç GÜVENÇ ${ }^{1}$ \\ ${ }^{1}$ Department of Materials Science and Engineering, Faculty of Engineering, Anadolu University, Eskişehir, 26470, Turkey
}

\begin{abstract}
A procedure for data collection and processing was developed to conduct accurate kinetic analysis in pressure assisted sintering techniques, such as hot pressing (HP) and spark plasma sintering (SPS). Densification of $\mathrm{MgAl}_{2} \mathrm{O}_{4}$ by $\mathrm{SPS}_{\text {was }}$ chosen as a model system, where the kinetics were analyzed by utilizing the modified creep equation. Displacement data used in the equation was gathered by path measurement system (PMS) of the SPS equipment. Effects of temperature control accuracy, load cell accuracy and resolution of the PMS on the reliability of collected displacement data were evaluated. Dilution of the data in order to reduce the noise in strain rate values caused by the low resolution of the PMS system, which is only $10 \mu \mathrm{m}$, was observed to affect calculated stress exponents (n), significantly. Different $\mathrm{n}$ values in the range of 1.7-2.8 in a narrow interval of 83-86\% relative densities were found as a function of dilution degree. On the other hand, differentiating the strain with respect to the time interval of every single $10 \mu \mathrm{m}$ displacement was shown to provide more consistent results. $\mathrm{n}$ values of $\approx 2.2$ with a standard deviation of 0.15 were calculated for the same density intervals.
\end{abstract}

Keywords: Formal sintering analysis, Modified creep equation, Spark plasma sintering

\section{INTRODUCTION}

Formal sintering analysis to reveal the densification mechanism in pressure assisted sintering techniques such as hot pressing (HP) and spark plasma sintering (SPS) usually utilize modified creep equation where creep rates are transformed into normalized densification or strain rates as given in the following equation [1-13]:

$$
\frac{1}{\rho} \frac{d \rho}{d t}=\frac{H D \phi^{n}}{G^{m} k T} p_{a}^{n}
$$

In Eq. (1) $\rho$ is relative density, $t$ is time, $H$ is numeric constant, $D$ is diffusion coefficient, $\phi$ is stress intensification factor, $p$ is applied pressure, $G$ is grain size, $k$ is Boltzmann constant, $T$ is absolute temperature and $\mathrm{n}$ and $\mathrm{m}$ are stress and grain size exponents, respectively. To determine the dominant sintering mechanism, basically $\mathrm{n}$ and $\mathrm{m}$ exponents are calculated from a given strain rate data [1-12]. These data is gathered during densification, by the linear variable displacement transducer (LVDT) or path measurement system (PMS) of a HP or SPS equipment [2-7]. As distinct from a dilatometer or a thermo-mechanical analyzer (TMA), these equipments are not dedicated to formal sintering analysis. Firstly, samples are more prone to higher temperature gradients during analysis since the hot zone volume of these equipment are much larger in comparison to the volume of a TMA furnace. Secondly, moderate to high loading capacities of the equipment limits the sensitivity and the accuracy of load cells. Most importantly, the resolution values of the LVDTs or PMSs of such equipment are in the micron-scale, which is not comparable with the nano-scale resolution values that most of the TMAs have. Despite these shortcomings, HP and SPS are widely used in formal kinetic studies. However, different findings might sometimes be reported even in the analysis of the same material.

*Corresponding Author: ismailoo@anadolu.edu.tr 
Ting and $\mathrm{Lu}$ [2], calculated a stress exponent of $\mathrm{n} \geq 3$ and showed that the dominant densification mechanism of hot pressed $\mathrm{Mg}$-spinel $\left(\mathrm{MgAl}_{2} \mathrm{O}_{4}\right)$ is climb controlled dislocational creep at the earlier stages of densification. As the compact densifies the mechanism changes into Naborro-Herring diffusional creep with an exponent of 1. Morita et al. [4], reported similar results for SPS of Mgspinel. Plastic flow caused by partial dislocation motion is responsible for densification at earlier stages or lower densities, whereas the dominant mechanism changes into diffusional creep at higher densities. However, they also indicated a transition region where grain boundary sliding is active, with a calculated exponent of 2. Distinct from these studies, Bernard-Grenger et al. [3], did not observe a significant dislocation activity in SPS of Mg-spinel. They found a stress exponent of 2 and a grain size exponent of 1 in their anisothermal kinetic studies and proposed that grain boundary sliding accommodated by oxygen lattice diffusion governs densification. Discrepancies in the findings of these studies may be attributed to different powders and processes used in the analysis. However, lack of a detailed analysis protocol, which may overcome the shortcomings of equipment used in these studies, should also be taken into consideration in order to explain the different densification mechanisms observed during the pressure assisted sintering of $\mathrm{Mg}$-spinel.

In this study, a procedure for data collection and processing was developed to conduct accurate formal analysis by HP and SPS equipment. Densification of Mg-spinel by SPS technique was chosen as a model system, where the kinetics were analyzed by the utilization of modified creep equation (Eq. (1)). It should be emphasized that calculated $n$ values were only utilized to evaluate the data processing methodology. Calculated stress (n) and grain size (m) exponents, activation energies and findings on the dominant densification mechanisms during SPS of Mg-spinel will be published elsewhere.

\section{MATERIALS AND METHODS}

Stoichiometric Mg-spinel powder (Baikowski, S30CR, France) was used to perform sintering experiments in this study. Sintering analysis were conducted by FCT Systeme GmbH, HP D 25/1 spark plasma sintering equipment (Germany). Powders were directly loaded into graphite SPS die that was lined with a graphite foil. Two other foil pieces were also placed between the powder and the punches. The graphite foils each in $2 \mathrm{~mm}$ thickness were pressed down prior to usage to prevent large deformation during analysis. Although a portion of this deformation is removed from the data by subtracting the displacement of blank experiments, using less deformable thin layers was observed to provide more consistent results. A thin layer of hexagonal boron nitride spray was applied to foils to prevent powder sticking. Independently from the analysis pressure, all powder samples were pressed under $60 \mathrm{MPa}$ in SPS prior to sintering to ensure similar green packing for every single experiment. Height of the powder compacts required to calculate the strain were recorded by considering the punch and foil dimensions. Strain was calculated from the obtained displacement data by the following equation:

$$
=\frac{l_{s} \quad l_{0} \quad l_{g}}{l_{s_{0}}} T
$$

where $\varepsilon$ is the strain, $\Delta \mathrm{l}_{\mathrm{s}}$ is the dimensional change of the sample, $\Delta \mathrm{l}_{0}$ is the first displacement recorded by the PMS, $\Delta \mathrm{l}_{\mathrm{g}}$ is the dimensional change of the graphite die, $\Delta \mathrm{l}_{\mathrm{s} 0}$ is the compact height, $\alpha$ is the thermal expansion coefficient of $\mathrm{Mg}$-spinel and $\mathrm{T}$ is temperature.

Effect of load cell accuracy and the resolution of PMS system on the reliability of the obtained data were evaluated from the calculated stress exponent, $n$. Isothermal analyses were performed at $1200^{\circ} \mathrm{C}$ under different pressure profiles in the range of $15-45 \mathrm{MPa}$ to determine the stress exponent. All of the analyses were conducted below $90 \%$ relative density to minimize the effect of grain growth. 


\section{RESULTS AND DISCUSSION}

\subsection{Accuracy of Temperature Measurement}

Stress exponent (n) is basically determined by calculating the slope of $\ln [(1 / \rho)(d \rho / d t)]-\ln (\phi p)$ graph. As seen in Eq.(1), densification rate (d $/$ dt) is not only a function of effective stress $(\phi p)$, but depends on diffusion, energy conversion factor $(\mathrm{kT})$ and the grain size, as well. In order to decrease the number of variables by removing the effects of diffusion and $\mathrm{kT}, \ln [(1 / \rho)(\mathrm{d} \rho / \mathrm{dt})]-\ln (\phi \mathrm{p})$ graph is plotted using isothermal data. Effect of grain growth can also be underestimated as long as the analysis is conducted below $90 \%$ relative density. Since the data is obtained from a series of isothermal analysis, any deviation in real and programmed temperature would not cause an error in the calculation of $\mathrm{n}$, assuming that the deviation is constant in every experiment. However, it is important to know, in which temperature the dominant densification mechanism proposed by the calculated $\mathrm{n}$ number, is exactly active. Besides, deviations in real temperature may cause significant error in activation energy calculations. Therefore, the first step of a formal sintering analysis should be the accuracy testing of temperature reading.

Pyrometer of the SPS equipment used in this study measures the temperature from a hole drilled to the punch, which is $5 \mathrm{~mm}$ above the sample. Such a low measuring distance from a highly conductive graphite material enables to record almost the real temperature of the sample, as long as the pyrometer functions correctly. In the literature, temperature accuracy of SPS is usually tested by melting pure metals, such as copper, silver, gold and platinum, which are embedded in a ceramic powder bed, i.e. alumina $[14,15]$. However, this method only allows checking the temperature at the melting point of the metal used. Although, increasing the control range is always possible by using different metals, it is not economic because of the high cost of pure metals. In this study, a practical approach was proposed, which does not require any reference material and that allows to check how well the scheduled profile is being followed especially at high heating rates, as well as allowing to check the accuracy of the peak temperature. In this method, basically the thermal expansion of the graphite punches placed in an empty graphite die are followed for a given temperature profile (Figure 1). The initial negative displacement seen in Figure 1 is a result of elastic deformation of the punches under the applied load. Afterwards, the punches exhibit thermal expansion as the temperature increases. As can be derived from the following equation, where $\mathrm{L}$ is the length, $\alpha$ is the coefficient of thermal expansion (CTE) and $\mathrm{T}$ is temperature, displacement rate $(\mathrm{dL} / \mathrm{dt})$ changes relative to heating rate (dT/dt) by a factor of $\alpha^{*} \mathrm{~L}$.

$$
\mathrm{dL}=\alpha \mathrm{LdT}
$$

However, such a regime is not seen in Figure 1, where the displacement follows the temperature at the high heating regime $\left(50^{\circ} \mathrm{C} / \mathrm{min}\right)$ and then deviates at the low heating profile $\left(10^{\circ} \mathrm{C} / \mathrm{min}\right)$. Calculated slope of the displacement curve from a CTE coefficient of $8.1 * 10^{-6} /{ }^{\circ} \mathrm{C}$ (CTE for HPD grade graphite used in this study) was found as 0.945 . Using a factor of 2000 between the axis of temperature and displacement yields a slope of 0.83 for temperature at the high heating regime. Apart from the calculated values, same slopes of the curves at this region indicate a deviation in the temperature reading or a significant temperature gradient in the die. Therefore, high heating rates should be avoided especially for formal sintering analysis. 


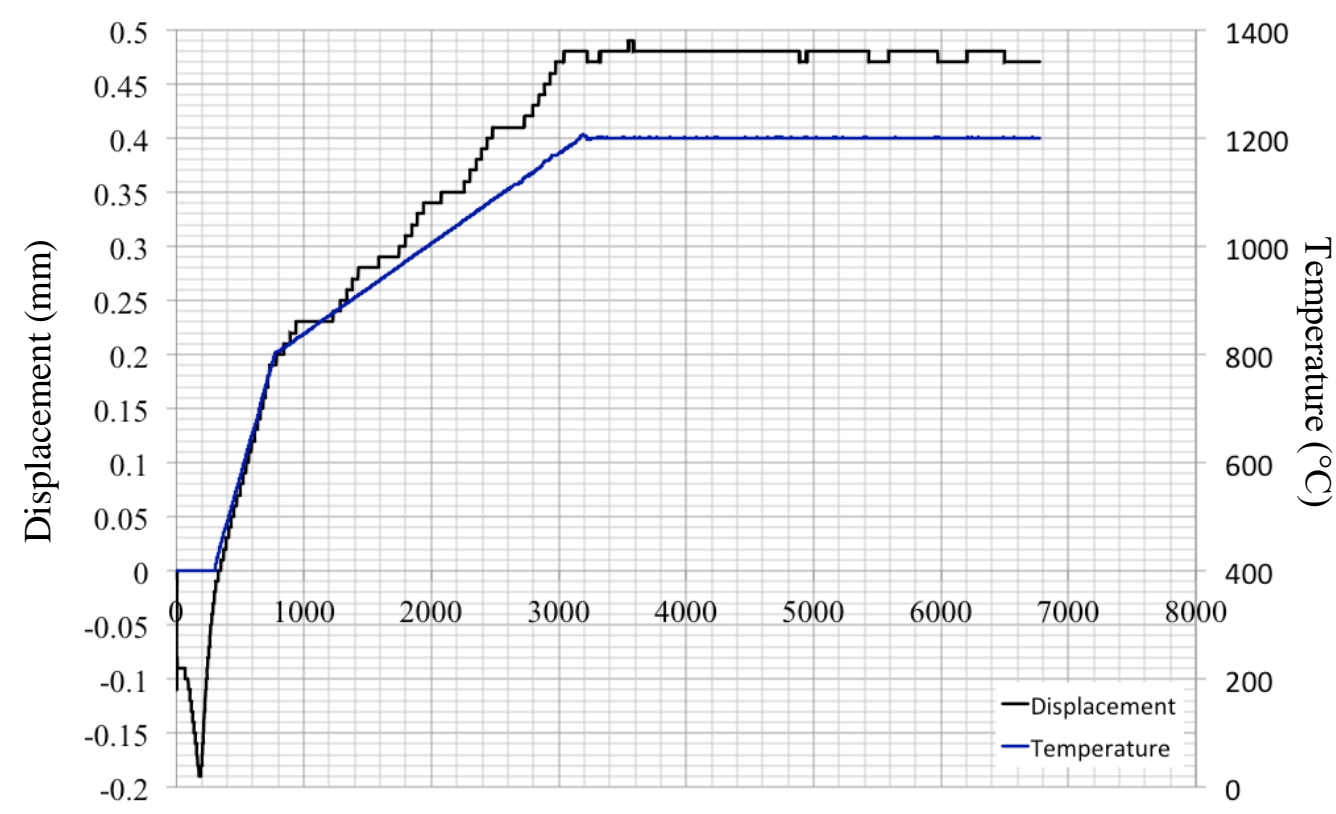

Time (s)

Figure 1. Displacement of graphite punches placed in an empty graphite die for the plotted temperature profile

Accuracy of the peak temperature was also checked from theoretically calculated linear thermal expansion values assuming a constant CTE. A total expansion of $\approx 0.666 \mathrm{~mm}$ was calculated for a 70 mm punch length and $1175^{\circ} \mathrm{C}$ temperature difference. A very close expansion value of $0.67 \mathrm{~mm}$ (Figure 1) that is recorded by PMS suggests a high accuracy for temperature reading when the equilibrium is reached. Although the pyrometer is highly accurate, it should be noted that the deviation of the sample temperature from the scheduled value may also be correlated with the thermal and electrical properties of the sample and the die, and the die dimensions, as well $[15,16]$.

\subsection{Load Cell Accuracy}

One of the objectives of formal SPS and HP kinetic studies is to determine the transition stress where the dominant densification mechanism is changing. Ting and Lu [2], reported an effective transition stress of $\approx 26 \mathrm{MPa}$ for the HPing of stoichiometric Mg-spinel, where the densification mechanism switches from dislocation motion to diffusion-controlled. Bratton et al. [5], reported that this transition occurs at an applied stress of $\approx 27 \mathrm{MPa}$ for the sintering conditions they used. Apart from the reported values, a highly precise transition stress can only be determined by sintering analysis where small pressure increments are utilized. Although, the minimum pressure increment value that can be used is restricted by the load cell accuracy and the die cross-section, kinetic studies in the literature do not usually correlate pressure profiles with these parameters [2-5].

Figure 2 shows the recorded forces by the load cell of SPS at different applied loads. As seen, there is deviation up to $\pm 1 \mathrm{kN}$ in each curve independently from the applied load, which suggest that the accuracy of the load cell is $1 \mathrm{kN}$. For a standard die diameter of $20 \mathrm{~mm}$ that is widely used in most of the SPS studies, $1 \mathrm{kN}$ corresponds to $3.2 \mathrm{MPa}$ pressure. Therefore an accurate analysis with this diameter of die requires at least 6.4 MPa pressure increments. 


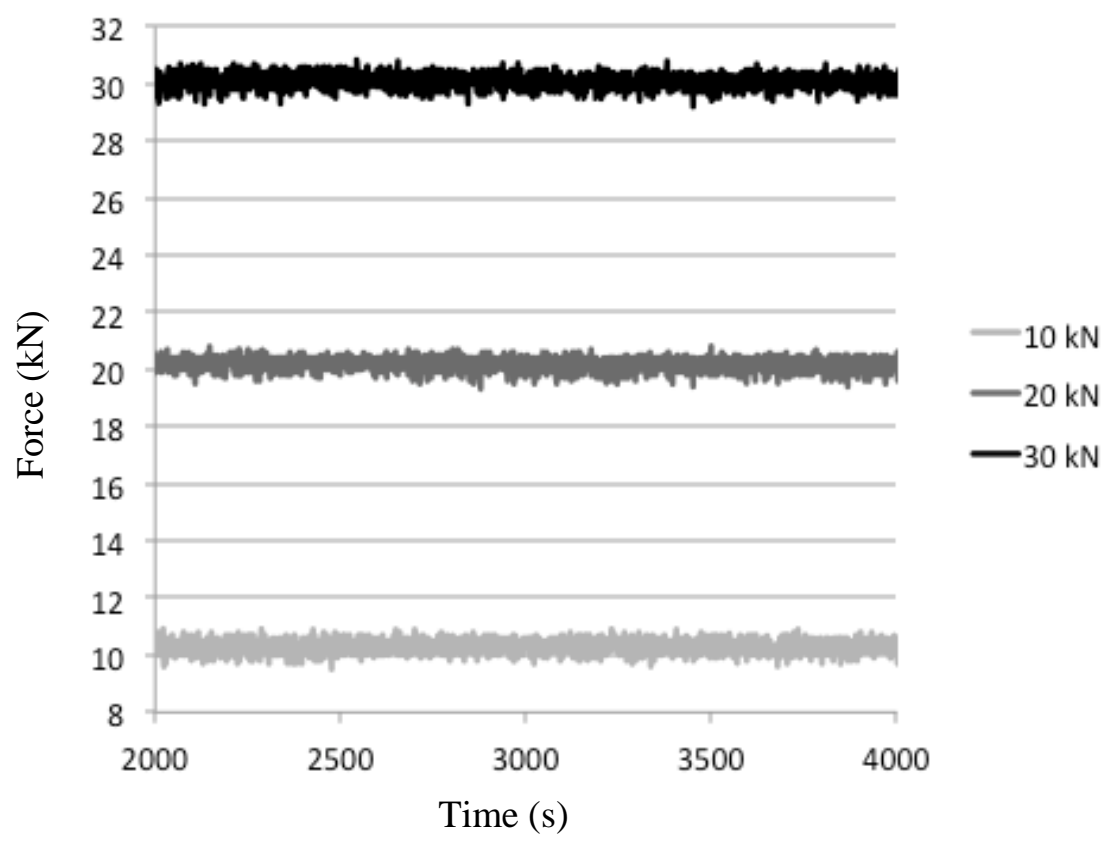

Figure 2. Force reading of the load cell at different applied loads

A practical way to eliminate this constrain is to use dies with larger cross-sections. As seen in Figure 3 , percentage of error in pressure decreases significantly for a small increase in die diameter. Using larger dies would also enable to analyze higher powder compacts by decreasing the pressure gradients (benefit of higher powder fills will be discussed in the next chapter). In other words, larger dies provide to stay in the limits of critical uniaxial pressing aspect ratio for high powder fills. On the other hand, increasing the die diameter may result in thermal gradients where the isolator compact is heated from the die walls. Optimization between these parameters can be easily done by determining the critical die diameter and powder fill, where the thermal and pressure gradients start to cause significant density gradients. Microstructural analysis or density measurements for such an optimization were not performed in this study. It should be noted that such optimizations are not only crucial for formal sintering analysis, but they are important for controlled sintering experiments, as well.

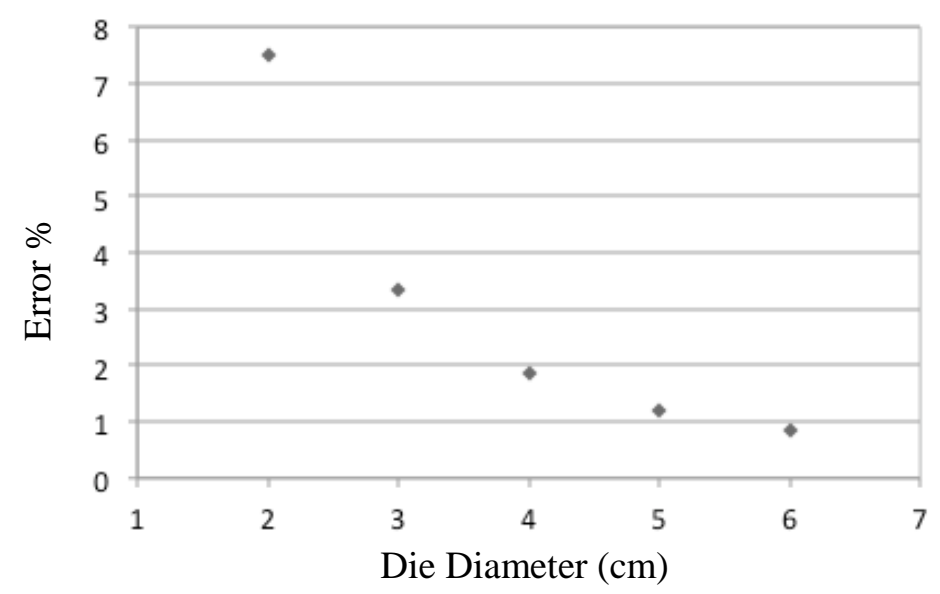

Figure 3. Error \% in pressure as a function of die diameter for $42 \mathrm{MPa}$ applied pressure 


\subsection{Resolution of Path Measurement System}

The most challenging issue of the formal sintering analysis by SPS is caused by the resolution of path measurement system, which is only $10 \mu \mathrm{m}$ for the equipment used in this study. Figure 1 is intentionally presented by gridlines that are spaced $10 \mu \mathrm{m}$ apart to show the resolution of PMS. As seen, the displacement follows a path, which is formed by steps of $10 \mu \mathrm{m}$ height. Considering the huge size of the equipment and structure of the test fixture that is composed of different parts, i.e. electrodes, spacers and die, each made of different materials, this resolution may be thought to be pretty high. However, when compared with the resolution of a TMA that is in the nanometer scale, it can be seen that a resolution of $10 \mu \mathrm{m}$ is inadequate for formal sintering analysis. In contrast to free sintering, where the densification progress by the shrinkage in three dimensions (Eq.4), sintering strain is constrained to only thickness direction in SPS (Eq.5). This can compensate for low resolution up to a minor point.

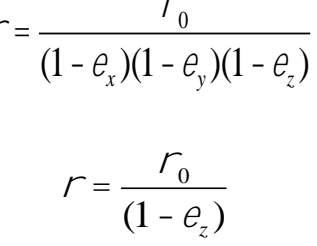

The only practical way to reduce the resolution problem is increasing the powder fill height. As pointed out in the previous section, this may cause density gradient as a result of increment in pressure gradient. For an initial height of 7-8 mm, ultimate microstructures did not indicate a finding that would be caused by such a gradient. However, even with the high initial height, obtained data needed to be processed to differentiate the strain, especially at low strain levels. Since the PMS is only able to detect $10 \mu \mathrm{m}$ displacements, data usually consist of long durations with the same displacement value, which cause high noise during the calculation of strain rates. Two different data processing methodologies were applied to reduce the noise and to differentiate the strain. At the first one, simply the data was diluted. Strain rates were calculated by taking one data in each of 50 or in each of 100 . Figure $4 \mathrm{a}$ and $\mathrm{b}$ show the results of these calculations by the plots of strain rate as a function of time. As seen, the noise decreases as dilution amount increases. In the second methodology, the strain was differentiated with respect to the time interval of every single $10 \mu \mathrm{m}$ displacement, which is the smallest value that can be detected. A code in Matlab (MATLAB 2014b, United States) was written to determine the time intervals. Figure 5 shows the strain rate as a function of time curve where the rate values were derived by second methodology. 
Özer and Güvenç / Anadolu Univ. J. of Sci. and Technology A - Appl. Sci. and Eng. 18 (2) - 2017

a)

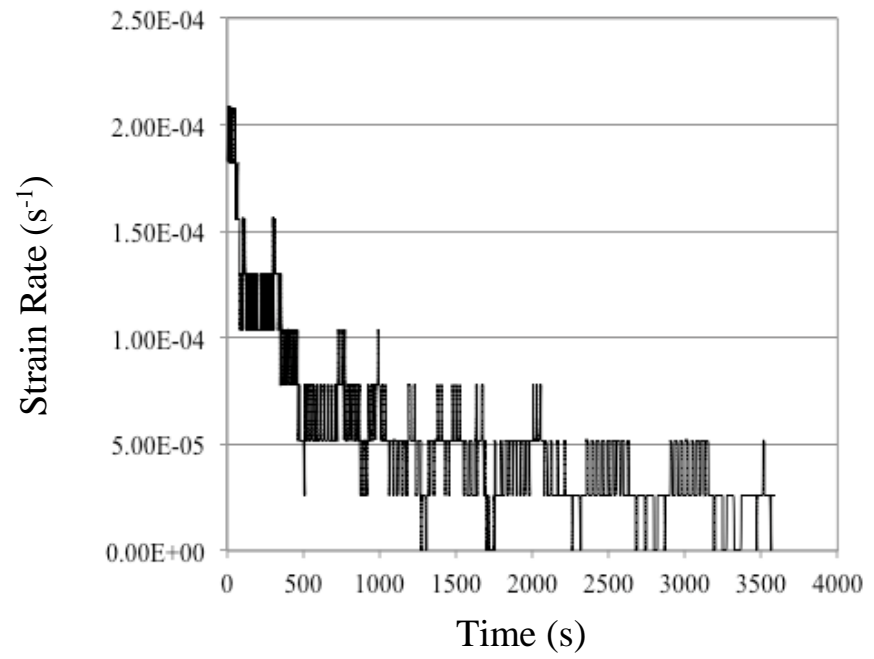

b)

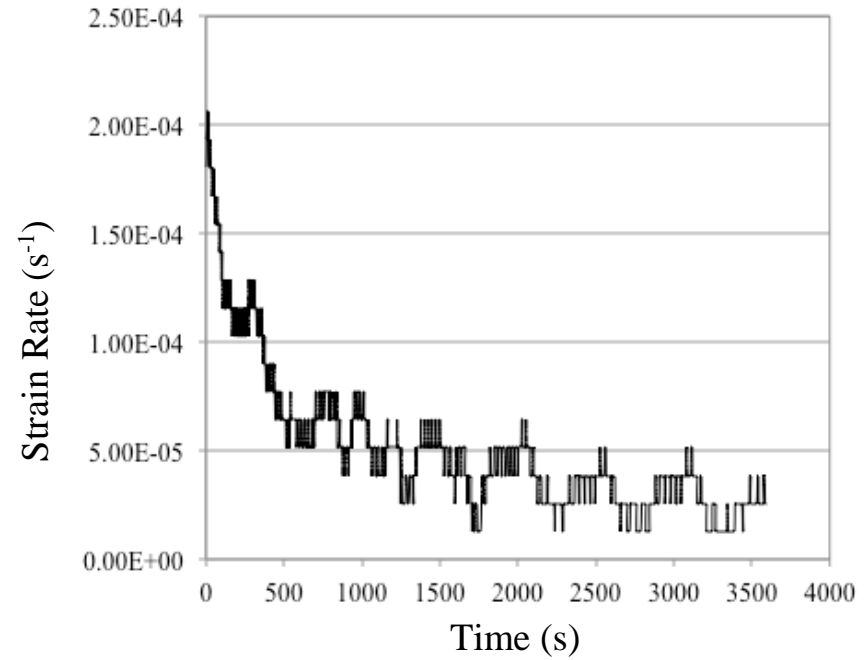

Figure 4. Strain rate vs. time curves. Diluted by taking one data $\mathbf{a}$ ) in each of 50 and $\mathbf{b}$ ) in each of 100

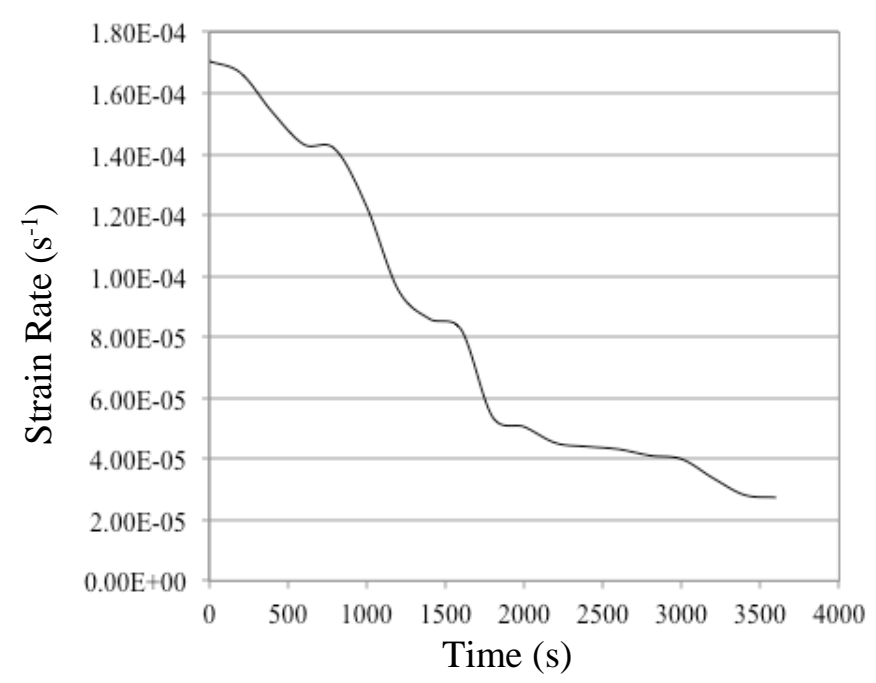

Figure 5. Strain rate vs. time curve where the rate values were derived by second data processing methodology as explained in the text. 
Calculated strain rate values with two different data processing methods were used to determine the stress exponents in a small density interval, 83-86\%. Figure $6 \mathrm{a}$ and $\mathrm{b}$ present the stress exponents derived from a sintering temperature of $1200^{\circ} \mathrm{C}$ and from the strain rates calculated by two different methodologies. As seen, exponents calculated with the strain rates derived from the second methodology (Figure $6 \mathrm{~b}$ ) yielded a number of $\approx 2.2$, which suggest that the grain boundary sliding (GBS) is active in this region. A low standard deviation of 0.15 indicates that the calculated strain rates by this methodology provide consistent stress exponent values. On the other hand, strain rates derived from the first processing methodology yielded stress exponents between 1.7-2.8 (Figure $6 \mathrm{a}$ ). An exponent between 2 and 3, which indicate GBS and dislocation induced plastic flow, respectively may suggest a transition region where both mechanisms are competing. However, lack of a trend in the numbers (Figure 6 a) does not point at such a transition region. High deviation in the calculated $n$ numbers is probably a result of the method used in the derivation of strain rates. Poor fitting of the curves in Figure $6 \mathrm{a}$, when compared with Figure $6 \mathrm{~b}$ is also an indication of inadequacy in the data dilution method. Obviously, strain rate calculations by the second processing method provide less error in comparison to the first method.

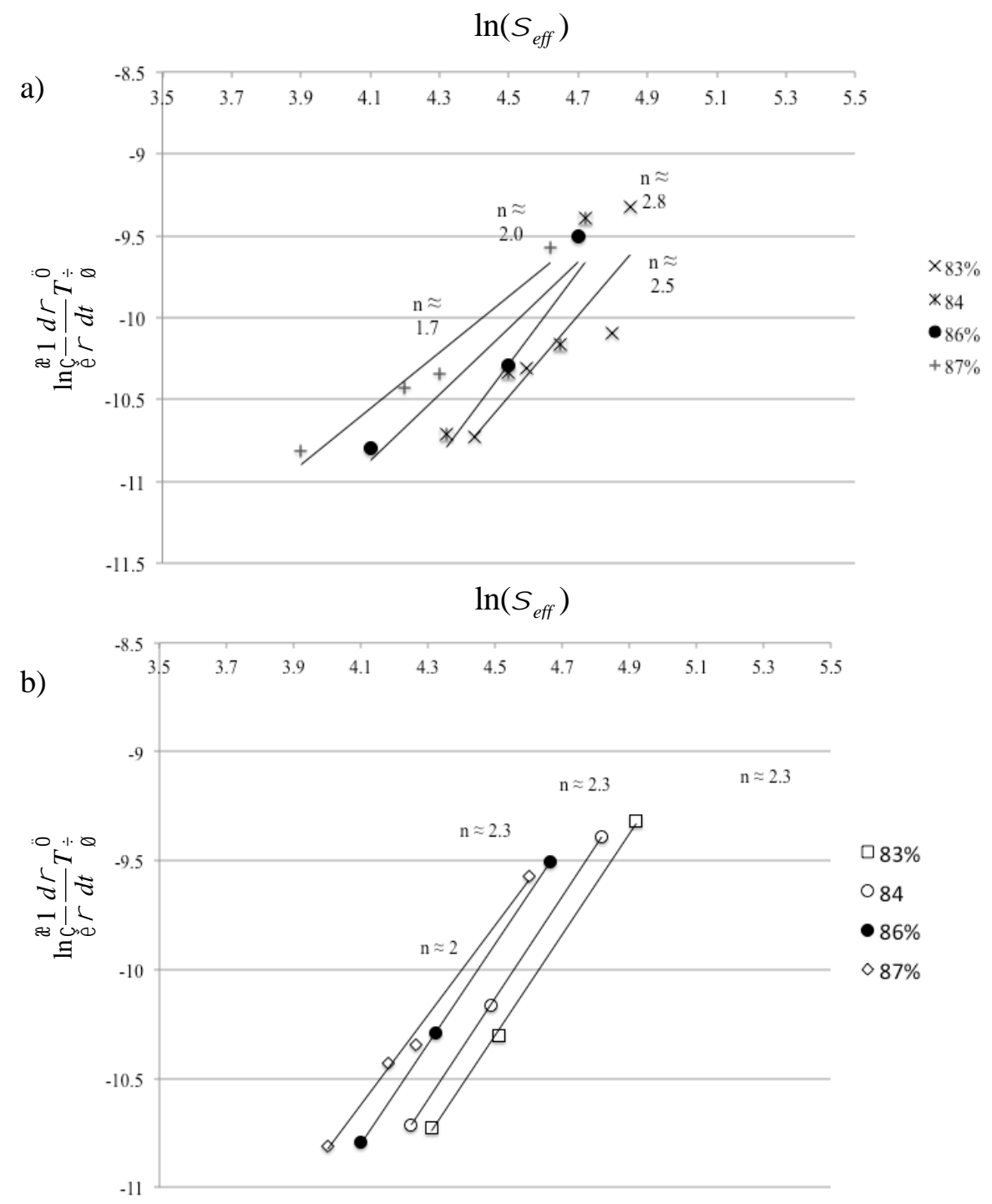

Figure 6. Stress exponents derived from a sintering temperature of $1200^{\circ} \mathrm{C}$ and from the strain rates calculated by a) the first and b) the second data processing methodologies 
Özer and Güvenç / Anadolu Univ. J. of Sci. and Technology A-Appl. Sci. and Eng. 18 (2) - 2017

\section{CONCLUSIONS}

A procedure for data collection and processing was developed to conduct accurate kinetic analysis in pressure assisted sintering techniques, such as hot pressing (HP) and spark plasma sintering (SPS). It was shown that, checking the accuracy of temperature measurement which should be the first step of every formal sintering analysis, can be simply performed by following the deviation between the calculated and measured thermal expansions of graphite punches for a given temperature profile. It was also proposed that a precise transition stress measurement cannot be performed unless the pressure profiles are designed considering the load cell accuracy and die diameters. Moreover, optimizing the experimental setup parameters such as die diameter and powder fill height which can partially overcome the constrains of load cell accuracy and the PMS resolution helps only to collect a more accurate data, but does not necessarily provide the correct results, if used as raw. Data processing was also shown to be crucial for formal analysis. Dilution of the data in order to reduce the noise in strain rate values caused by the low resolution of the PMS system was observed to affect calculated stress exponents ( $\mathrm{n}$ ), significantly. Different $\mathrm{n}$ values in the range of 1.7-2.8 in a narrow interval of $83-86 \%$ relative densities were found. On the other hand, differentiating the strain with respect to the time interval of every single $10 \mu \mathrm{m}$ displacement, which is the minimum detectable movement was shown to provide more consistent results. $\mathrm{n}$ values of $\approx 2.2$ with a standard deviation of 0.15 were calculated for the same density intervals.

\section{ACKNOWLEDGEMENTS}

The research for this paper was financially supported by The Scientific and Technological Research Council of Turkey (TUBITAK) under the contract number of 114M232. Authors would like to thank Emin GERMEN for writing a MATLAB code that simplified the data analysis.

\section{REFERENCES}

[1] Rahaman MN. Ceramic Processing and Sintering. 2nd ed. New York, NY, USA: Marcel Dekker Inc., 2004.

[2] Ting C-J, Lu, H-Y. Hot pressing of magnesium aluminate spinel - I.kinetics and densification mechanism. Acta Mater 1999; 3: 817-830.

[3] Bernard-Grange G, Benameur N, Addad A, Nygren M, Guizard C, Deville S. Phenomenological analysis of densification mechanism during spark plasma sintering of $\mathrm{MgAl}_{2} \mathrm{O}_{4}$. J Mater Res 2009; 6: 2011-2020.

[4] Morita K, Kim B-N, Yoshida H, Hiraga K. Densification behavior of a fine-grained $\mathrm{MgAl}_{2} \mathrm{O}_{4}$ spinel during spark plasma sintering (SPS). Scripta Materialia 2010; 63: 565-568.

[5] Bratton RJ, Terwilliger GR, Ho SM. Densification phenomena in the hot-pressing of spinel. J Mater Sci 1972; 1363-1368.

[6] Du X, Zhang Z, Wang Y, Wang J, Wang W, Wang H. Hot-pressing kinetics and densification mechanisms of boron carbide. J Am Ceram Soc 2015; 98: 1400-1406.

[7] Ting C-J, Lu H-Y. Hot pressing of magnesium aluminate spinel - II. microstructure development. Acta Mater 1999; 3: 831-840.

[8] Aman Y, Garnier V, Djurado E. Spark plasma sintering kinetics of pure $\alpha$-alumina. J Am Ceram Soc 2011; 9: $2825-2833$. 
Özer and Güvenç / Anadolu Univ. J. of Sci. and Technology A-Appl. Sci. and Eng. 18 (2) - 2017

[9] Santanach JG, Weibel, A, Estourne's, C, Yang Q, Laurent Ch, Peigney A. Spark plasma sintering of alumina: Study of parameters, formal sintering analysis and hypotheses on the mechanism(s) involved in densification and grain growth. Acta Mater 2011; 59: 1400 - 1408.

[10] Bernard-Granger G, Guizard C. Densification mechanism involved during spark plasma sintering of a codoped $\alpha$-alumina material: Part I. Formal sintering analysis. J Mater Res 2009; 1: 179 - 186.

[11] Nixon RD, Davis RF. Diffusion-accommodated grain boundary sliding and dislocation glide in the creep of sintered alpha silicon carbide. J Am Ceram 1992; 7: 1786 - 1795.

[12] Guillion O. Effects of applied stress and heating rate on field assisted sintering. RHR Castro and K. van Benthem (eds.), Sintering, Engineering Materials 35 2013; 195 - 213.

[13] Chakravarty D, Chokshi AH, Nixon RD, Davis RF. Direct characterizing of densification mechanisms during spark plasma sintering. J Am Ceram Soc 2014; 3: 765-771.

[14] Eriksson, M. Spark plasma sintering enhancing grain sliding, deformation and grain size control. Department of Materials and Environmental Chemistry, Stockholm University, PhD Thesis 2010.

[15] Guillon O, Langer J. Master sintering curve applied to the field-assisted sintering technique. J Mater Sci 2010; 45: 5191-5195.

[16] Gullion O, Gonzalez-Julian J, Dagatz B, Kessel T, Schierning G, Rathel J, Herrmann M. Field assisted sintering technology/spark plasma sintering: mechanisms, materials and technology developments. Adv Eng Mat 2014; 1-20. 